Article

\title{
Energy and Resource Efficient Production of Fluoroalkenes in High Temperature Microreactors
}

\author{
Konstantin Mierdel ${ }^{1,2, *}$, Andreas Jess ${ }^{3,4}$, Thorsten Gerdes ${ }^{2,5}$, Achim Schmidt ${ }^{2}$ \\ and Klaus Hintzer ${ }^{6}$ \\ 1 Chair of Materials Processing, University Bayreuth, 95447 Bayreuth, Germany \\ Institut für innovative Verfahrenstechnik, InVerTec e. V., 95447 Bayreuth, Germany \\ Chair of Chemical Engineering, University Bayreuth, 95447 Bayreuth, Germany \\ Center of Energy Technology, University Bayreuth, 95447 Bayreuth, Germany \\ Chair of Ceramic Materials Engineering, Keylab Glasstechnology, 95447 Bayreuth, Germany \\ 3M Dyneon, 84508 Burgkirchen, Germany \\ * Correspondence: Konstantin.mierdel@uni-bayreuth.de; Tel.: +49-921-55-7211
}

Received: 2 August 2019; Accepted: 17 September 2019; Published: 24 September 2019

\begin{abstract}
Tetrafluoroethylene (TFE) and hexafluoropropylene (HFP) are the most common monomers for the synthesis of fluoropolymers at industrial scale. Currently, TFE is produced via multistep pyrolysis of chlorodifluoromethane (R22), resulting in a high energy demand and high amounts of waste acids, mainly $\mathrm{HCl}$ and HF. In this study, a new chlorine-free process for producing TFE and HFP in a microreactor is presented, starting from partially fluorinated alkanes obtained from electrochemical fluorination (ECF). In the microreactor, high conversion rates of $\mathrm{CHF}_{3}$, which is used as a surrogate of partly fluorinated ECF streams, and high yields of fluoromonomers could be achieved. The energy saving and the environmental impact are shown by a life cycle assessment (LCA). The LCA confirms that the developed process has economical as well as ecological benefits, and is thus an interesting option for future industrial production of fluoroalkenes.
\end{abstract}

Keywords: microreactor; fluoropolymers; tetrafluoroethylene (TFE); hexafluoropropylene (HFP); life cycle assessment (LCA)

\section{Introduction}

Fluoropolymers are high-tech materials with extraordinary properties (non-flammable, chemically stable, high dielectric strength, and operating temperatures up to $280^{\circ} \mathrm{C}$ ), and thus are not substitutable in numerous technical applications, for example, in the semiconductor/electronic industry, seal- and corrosion-resistant applications, or in future technologies for energy conversion like fuel cells [1]. The worldwide consumption of fluoropolymers was about 270,000 t per year in 2015 [2]. The most common polymer is polytetrafluoroethylene (PTFE) with $140,000 \mathrm{t} \mathrm{a}^{-1}$. The complete fluoropolymer production requires about 162,000 t of tetrafluoroethylene (TFE) and 41,000 $\mathrm{t}$ of hexafluoropropylene (HFP) per year [2]. In addition, partly fluorinated monomers like vinylidene fluoride (VDF) (43,000 $\left.\mathrm{t} \mathrm{a}^{-1}\right)$ and vinyl fluoride (VF) are necessary for polyvinylidene fluoride (PVDF) production, but also for different applications, such as fluorinated membranes or new binding systems in electrodes for lithium ion batteries $[3,4]$.

Industrial production: In contrast to "simple" monomers such as ethylene or propylene, which are produced in a one-step process (steamcracking), the production of fluoromonomers follows an expensive, multistage chemical chlorine-synthesis, which is called the R22 route [5,6]. The R22 route was first reported by Downing and Benning in 1945 [7]. This synthesis, as depicted in Table 1 for TFE, starts with the partial chlorination of methane to trichloromethane (Table 1, Equation (1)). In 
this reaction step, not only trichloromethane, but also mono- and dichloromethane are produced, which can only finally be converted into trichloromethane by a respective recycle to the reactor. The other synthesized by-product, tetrachloromethane, cannot be used in further reactions and must be incinerated and disposed of. Further, large amounts of $\mathrm{HCl}$ (three $\mathrm{mol} \mathrm{HCl}$ per mol methane) are formed in this reaction step. In the second synthesis step (Table 1, Equation (2)), trichloromethane and hydrogen fluoride, which is produced by the reaction of calcium fluoride and sulphuric acid, are converted to difluorochloromethane (R22) through the use of an antimony chloride catalyst. The third reaction step (Table 1, Equation (3)) consists of the pyrolysis of R22 to difluorocarbene and $\mathrm{HCl}$ at temperatures between $800{ }^{\circ} \mathrm{C}$ and $900{ }^{\circ} \mathrm{C}$ [8]. The gained difluorocarbene reacts immediately to tetrafluoroethylene (TFE) by dimerization (Table 1, Equation (4)).

Table 1. Reaction equations of the industrial R22 route.

\begin{tabular}{|c|c|c|}
\hline Reaction & $\Delta_{\mathrm{r}} \mathrm{H}_{298}[\mathrm{~kJ} / \mathrm{mol}]$ & Equation \\
\hline $\mathrm{CH}_{4}+3 \mathrm{Cl}_{2} \stackrel{450^{\circ} \mathrm{C}}{\rightarrow} \mathrm{CHCl}_{3}+3 \mathrm{HCl}$ & -305 & Equation (1) \\
\hline $\mathrm{CHCl}_{3}+2 \mathrm{HF} \stackrel{\mathrm{SbCl}_{5}}{\rightarrow} \mathrm{CHClF}_{2}+2 \mathrm{HCl}$ & 168 & Equation (2) \\
\hline $\mathrm{CHClF}_{2} \stackrel{800^{\circ} \mathrm{C}}{\rightarrow}: \mathrm{CF}_{2}+\mathrm{HCl}$ & 120 & Equation (3) \\
\hline $2: \mathrm{CF}_{2} \stackrel{800^{\circ} \mathrm{C}}{\rightarrow} \mathrm{C}_{2} \mathrm{~F}_{4}$ & -295 & Equation (4) \\
\hline
\end{tabular}

A closer look at the reaction steps in Table 1 illustrates that current TFE production leads to high amounts of unwanted by-products and waste acids, especially hydrochloric acid $(\mathrm{HCl})$ and hydrofluoric acid (HF). A drawback is also the contamination of $\mathrm{HCl}$ with low amounts of $\mathrm{HF}$ (around $1500 \mathrm{ppm}$ ), which makes further use or recycling of the acid impossible. In addition, current TFE production has a high energy demand for the separation, purification, recycling, or incineration of by-products. It is thus highly desirable to develop a chlorine-free and more energy efficient process to produce fluoromonomers.

Alternative reaction routes: The first invention of a chlorine-free synthesis of TFE was made in 1957 and involved an electric arc or a plasma process for the reaction of $\mathrm{CF}_{4}$ with coal particles to TFE. However, both processes need huge amounts of energy and achieve only low yields of TFE, and thus could not compete with the conventional R22 route $[9,10]$.

Another approach for the production of fluoromonomers is the pyrolysis of fluoroform (R23), which is a by-product through over fluorination of trichloromethane (Equation (2)) in the R22 route. The annual amount of this waste stream is about several millions of kg per year [11]. Pyrolysis of $\mathrm{CHF}_{3}$ is conducted by Hauptschein and Fainberg [12] at temperatures of 700 to $960{ }^{\circ} \mathrm{C}$, residence times about $0.6 \mathrm{~s}$ to about $0.08 \mathrm{~s}$, and atmospheric pressure. They reached high conversion rates of about $80 \%$ and yields of $\mathrm{C}_{2} \mathrm{~F}_{4}$ and $\mathrm{C}_{3} \mathrm{~F}_{6}$ of about $58.1 \%$. Additionally, Gelblum et al. [11] tries to utilize $\mathrm{CHF}_{3}$ waste streams by co-pyrolysing R23/R22 mixtures in the range of 690 to $775^{\circ} \mathrm{C}$ and contact times less than $2 \mathrm{~s}$. In the sole feed pyrolysis of $\mathrm{R} 23$ at $775{ }^{\circ} \mathrm{C}$, Gelblum et al. measured conversion rates of $\mathrm{CHF}_{3}$ below $1 \%$ and detected TFE as only product gas.

In contrast to R22, which was economically favorable earlier because of its availability as a general-purpose refrigerant, a new approach for a complete chlorine-free process is based on electro-chemical fluorination (ECF), where perfluorinated hydrocarbons are formed by reaction of anhydrous hydrofluoric acid (AHF) with the corresponding hydrocarbons. State-of-the-art ECF processes only provide partly- and perfluorinated alkanes, but no alkenes like TFE [13]. Therefore, an additional process step is necessary. Aschauer et al. [14] showed that high yields of TFE could be obtained in a microwave plasma, when the feed consists of perfluorinated alkanes like $\mathrm{C}_{2} \mathrm{~F}_{6}$ and $\mathrm{C}_{4} \mathrm{~F}_{10}$, which originated from ECF, as described by Schmeiser et al. or Nagase et al. (Table 2) $[15,16]$.

The problem of utilizing feed gases from ECF is the low selectivity to perfluorinated products obtained in this process. Depending on the hydrocarbon used as feed in the ECF, up to $70 \%$ of the product spectrum consists of only partly fluorinated alkanes (Table 2) [15]. Production of 1000 
$\mathrm{t}$ perfluorinated compounds results in waste streams of about $400 \mathrm{t}$ of partly fluorinated residues. Further, hydrofluorocarbon by-products, for example, $\mathrm{CHF}_{3}, \mathrm{C}_{2} \mathrm{HF}_{5}$, and $\mathrm{C}_{2} \mathrm{H}_{2} \mathrm{~F}_{4}$, are produced, which are not allowed to be released into the atmosphere, because of their high global warming potential (GWP) (Table 2) [17].

Table 2. Product distribution of electro-chemical fluorination (ECF) $[16,18]$ and global warming potential (GWP) of fluorocarbons [17].

\begin{tabular}{|c|c|c|c|c|c|}
\hline & Reaction & $\begin{array}{c}\text { Total Current } \\
\text { Eff. }{ }^{\text {a }}[\%]\end{array}$ & \multicolumn{2}{|c|}{ Product Comp. [mol\%] } & \multirow{2}{*}{$\begin{array}{c}100 \mathrm{yr} \mathrm{GWP} \\
{[\mathbf{k g ~ C O} / / \mathbf{k g}]}\end{array}$} \\
\hline \multirow{4}{*}{$\mathrm{CH}_{4}$} & \multirow{4}{*}{$\mathrm{CH}_{4}+4 \mathrm{HF} \rightarrow \mathrm{CF}_{4}+4 \mathrm{H}_{2}$} & \multirow{4}{*}{48.2} & $\mathrm{CF}_{4}$ & 24.1 & \\
\hline & & & $\mathrm{CHF}_{3}$ & 11.0 & 11,700 \\
\hline & & & $\mathrm{CF}_{2} \mathrm{H}_{2}$ & 8.3 & 650 \\
\hline & & & $\mathrm{CFH}_{3}$ & 56.6 & 150 \\
\hline \multirow{5}{*}{$\mathrm{C}_{2} \mathrm{H}_{6}$} & \multirow{5}{*}{$\mathrm{C}_{2} \mathrm{H}_{6}+6 \mathrm{HF} \rightarrow \mathrm{C}_{2} \mathrm{~F}_{6}+6 \mathrm{H}_{2}$} & \multirow{5}{*}{65.0} & $\mathrm{C}_{2} \mathrm{~F}_{6}$ & 56.2 & 9200 \\
\hline & & & $\mathrm{C}_{2} \mathrm{~F}_{5} \mathrm{H}$ & 14.2 & 2800 \\
\hline & & & $\mathrm{C}_{2} \mathrm{~F}_{4} \mathrm{H}_{2}$ & 12.1 & 1000 \\
\hline & & & $\mathrm{CF}_{3} \mathrm{CFH}_{2}$ & 10.3 & 1300 \\
\hline & & & $\mathrm{C}_{2} \mathrm{~F}_{3} \mathrm{H}_{3}$ & 7.2 & 300 \\
\hline
\end{tabular}

a The calculation of current efficiency was based on the amount of current assumed to be necessary for forming fluorine with a discharging fluoride ion, which would react with the sample [18].

Currently, all partly fluorinated compounds must be incinerated (Table 3) under very high expenditure of energy. Another drawback of incineration is HF formation, which requires neutralization by bases like $\mathrm{NaOH}$ or $\mathrm{Ca}(\mathrm{OH})_{2}$ to receive depositable salts $\left(\mathrm{NaF}, \mathrm{CaF}_{2}\right)($ Table 3$)$.

Table 3. Reaction equation of incineration and pyrolysis of $\mathrm{CHF}_{3}$.

\begin{tabular}{ccc}
\hline & Reaction & Equation \\
\hline \multirow{3}{*}{$\mathrm{CHF}_{3}$ incineration } & $\mathrm{CHF}_{3}+\frac{1}{2} \mathrm{O}_{2} \rightarrow 3 \mathrm{HF}+\mathrm{CO}_{2}$ & Equation (5) \\
& $\mathrm{CH}_{4}+2 \mathrm{O}_{2} \rightarrow 2 \mathrm{H}_{2} \mathrm{O}+\mathrm{CO}_{2}$ & Equation (6) \\
& $\mathrm{Ca}(\mathrm{OH})_{2}+2 \mathrm{HF} \rightarrow 2 \mathrm{H}_{2} \mathrm{O}+\mathrm{CaF_{2 }}$ & Equation (7) \\
\hline \multirow{3}{*}{$\mathrm{CHF}_{3}$ pyrolysis } & $\mathrm{CHF}_{3} \rightarrow \mathrm{HF}+: \mathrm{CF}_{2}$ & Equation (8) \\
& $2: \mathrm{CF}_{2} \rightarrow \mathrm{C}_{2} F_{4}$ & Equation (9) \\
& $\mathrm{C}_{2} \mathrm{~F}_{4}+: \mathrm{CF}_{2} \rightarrow \mathrm{C}_{3} \mathrm{~F}_{6}$ & Equation (10) \\
\hline
\end{tabular}

To counteract the disadvantages of thermal utilization and to utilize the complete product spectrum of the ECF, in this study, partly fluorinated alkanes were proven regarding their suitability as starting material for fluoromonomer production. The respective process route of a utilization of partly fluorinated compounds for the production of TFE and HFP is illustrated in Figure 1. The synthesis starts with the supply of feed gas as by-products of ECF followed by pyrolysis for generation of monomers like TFE and HFP. The main advantages of this process are the utilization of cheap starting materials (currently waste streams) and the prevention of $\mathrm{HCl}$ waste acids. 


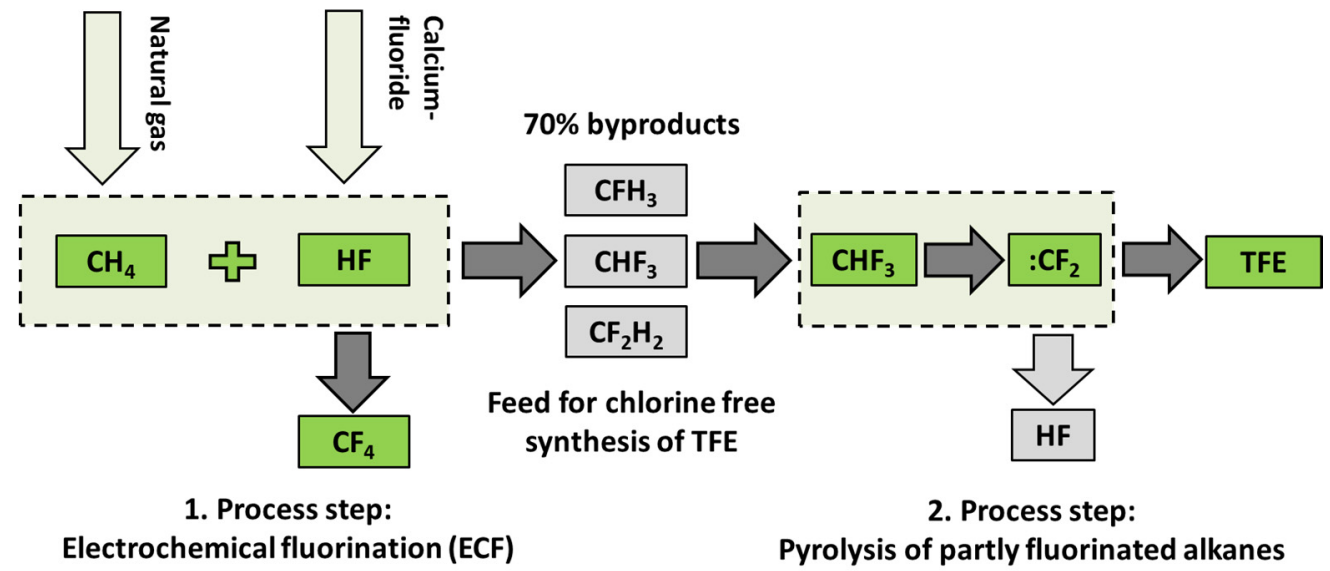

Figure 1. Design of a two-step chlorine-free process for fluoromonomer production.

In the field of fluorine chemistry and fluorine materials, the handling and processing of different reactions in microreactors are of growing relevance. The reasons for this trend are safer handling of hazardous reactants, a reduction in the (potential) exposure to toxic or hazardous chemical species, and higher process safety in terms of thermal runaway by efficient cooling. Moreover, the application of microreactors in fluorine containing reactions is beneficial in terms of reduced reaction volume, optimal process conditions, and thus higher yields of target products $[19,20]$. Scale-up of a microreactor process can be easily done just by numbering up [21]. Microreactors are also advantageous with regard to kinetic studies of highly exothermic or endothermic reactions, for example, here for the highly endothermic decomposition of fluorinated hydrocarbons. Compared with lab-scale fixed bed reactors, microreactors have a much higher surface-to-volume ratio, which enables very efficient heating or cooling, and thus almost isothermal operation. Hence, the determination of kinetic parameters is not hindered by limitations of heat and mass transfer [22].

In this work, the experimental results of the pyrolysis of partly fluorinated alkane $\mathrm{CHF}_{3}$ in a high temperature microreactor are presented. On the basis of the rate of $\mathrm{CHF}_{3}$ conversion, the kinetic data of this initial reaction step of pyrolysis (dehydrofluorination of $\mathrm{CHF}_{3}$ to $\mathrm{HF}$ and difluorocarbene) were determined. In consecutive reactions, fluorinated products such as tetrafluoroethylene (TFE), hexafluoroproplene (HFP), and perfluoroisobutene (PFiB) are formed. The measured product distribution was compared with a simulation of the pyrolysis using kinetic data from literature for these consecutive steps. The optimum reaction conditions for monomer formation were investigated. Finally, the ecological and economical potential of the process was evaluated by a life cycle assessment (LCA).

\section{Materials and Methods}

\subsection{Design of the Microreactor for the Pyrolsis of $\mathrm{CHF}_{3}$}

Pyrolysis of partly fluorinated alkanes for the production of fluoromonomers and determination of kinetic parameters was carried out in a high temperature siliconcarbide $(\mathrm{SiC})$ microreactor provided by $3 \mathrm{M}$ technical ceramics (Table 4 ).

Table 4. Technical data of SiC-microreactor.

\begin{tabular}{ccc}
\hline Material Properties & Unit & Value \\
\hline Density & $\mathrm{g} / \mathrm{cm}^{3}$ & $>3.15$ \\
Porosity & $\%$ & $<2.0$ \\
Grain size & $\mu \mathrm{m}$ & $2-10$ \\
Thermal conductivity $\lambda_{\mathrm{SiC}}$ at $25^{\circ} \mathrm{C}$ & $\mathrm{W} /(\mathrm{m} \mathrm{K})$ & 130 \\
Specific heat $\mathrm{CSiC}_{\mathrm{SiC}}$ at $25^{\circ} \mathrm{C}$ & $\mathrm{J} /(\mathrm{g} \mathrm{K})$ & 0.69 \\
\hline
\end{tabular}


The ceramic microreactor is depicted in Figure 2 and has a channel cross section of $1 \mathrm{~mm}^{2}$ and a reaction volume of $1.2 \mathrm{~mL}$. The microreactor design consists of four sections. An in- and outlet for the supplied and produced gases, a meander reaction zone, and a quenching zone. The microreactor has beneficial material properties like high thermal conductivity and specific heat, which provides almost isothermal operation, and thus an accurate measurement of the kinetics of $\mathrm{CHF}_{3}$ pyrolysis and of the subsequent fluoromonomer formation, respectively.

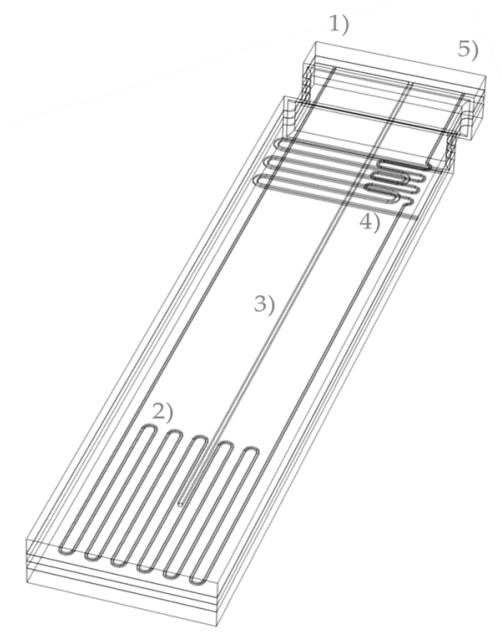

Figure 2. Microreactor used for the experiments: (1) gas inlet, (2) reaction zone, (3) thermocouple guide tube, (4) quenching system, and (5) product gas outlet.

\subsection{Measurement Setup for Pyrolsis of $\mathrm{CHF}_{3}$}

The setup for the determination of conversion of partly fluorinated substances is schematically depicted in Figure 3. It consisted of the gas supply, the high temperature micro reactor, the quenching with a following exhaust gas treatment, and the online gas chromatography (GC) analysis.

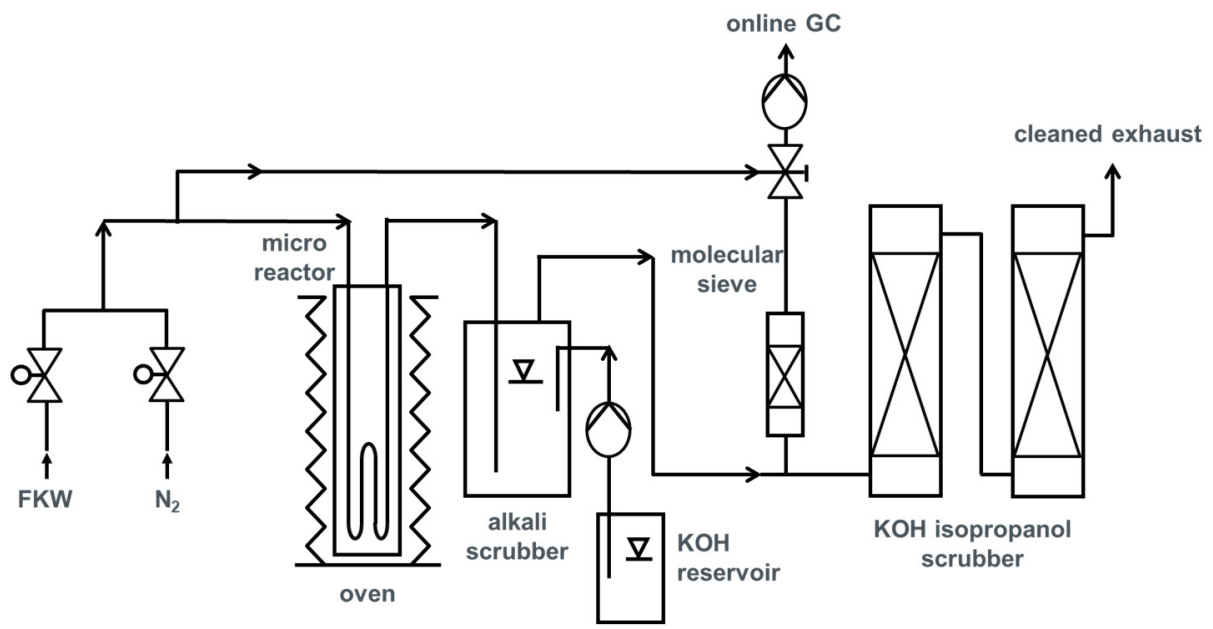

Figure 3. Flow sheet of the measurement setup for the pyrolysis of partly fluorinated alkanes.

$\mathrm{CHF}_{3}$ was supplied by Air Liquide with purities of $99.95 \%$ and $\mathrm{N}_{2}$ by Sauerstoffwerke Friedrichshafen $\mathrm{GmbH}$ with purities of $99.9 \%$. Mass flow controllers from Bronkhorst (EL-FLOW F-201CV) delivered the gases. The volumetric flow rate of fluoroform was varied from 0.25 to $5 \mathrm{~mL} \mathrm{~min}{ }^{-1} \cdot \mathrm{N}_{2}$ was used as inert carrier gas to adjust a volumetric content of $10 \%$ fluoroform in the feed stream. The microreactor was placed in a tubular electric furnace and heated to the desired constant temperature. The reaction temperature was monitored by one thermocouple placed in the 
meander shaped reaction zone (see Figure 2). After passing through the microreactor, the product gas was quickly quenched below $100^{\circ} \mathrm{C}$ to avoid consecutive reactions of TFE to di- or other oligomers. Additionally, hydrogen fluoride (HF) formed through the pyrolysis was neutralized with $\mathrm{KOH}(40 \mathrm{~g} / \mathrm{L})$ during passage through a washing bottle. The HF-concentrations were determined by $\mathrm{pH}$ probe, Knick SE555X/1-NMSN, placed in the washing bottles. The moisture behind the washing column was removed via molecular sieve of $0.3 \mathrm{~nm}$ (Metrohm Ion analysis). For the detection of the product gas distribution, an online gas chromatography (GC) HP 6890 equipped with a thermal conductivity detector (TCD) and a Carbopack C33 column ( $6 \mathrm{~m}, 5 \%$ picric acid) was used. The GC was operated in the temperature range from 40 to $110^{\circ} \mathrm{C}$, with a temperature ramp of $10 \mathrm{~K} / \mathrm{min}$ and a dwell time of $5 \mathrm{~min}$ at $110^{\circ} \mathrm{C}$. The detector ran at a temperature of $200^{\circ} \mathrm{C}$ and the injection temperature was $150{ }^{\circ} \mathrm{C}$.

\subsection{Pyrolysis Reaction, Kinetic Modeling, and Life Cycle Assessment (LCA) for the Pyrolsis of $\mathrm{CHF}_{3}$}

Experimental procedure: Before each pyrolysis experiment, the microreactor was purged with $\mathrm{N}_{2}$. The microreactor was then heated to the desired reaction temperature under $\mathrm{N}_{2}$ atmosphere. After reaching the target temperature, $\mathrm{CHF}_{3}$ was supplied. The pyrolysis experiments were conducted at temperatures of $775-875{ }^{\circ} \mathrm{C}$, residence times of $0.4-2.5 \mathrm{~s}$, a molar ratio of $\mathrm{CHF}_{3}$ to $\mathrm{N}_{2}$ of 0.1 , and at almost atmospheric pressure (Table 5).

Table 5. Experimental parameters of $\mathrm{CHF}_{3}$ pyrolysis.

\begin{tabular}{ccc}
\hline Parameters & Unit & Range \\
\hline Temperature & ${ }^{\circ} \mathrm{C}$ & $775-875$ \\
Pressure & $\mathrm{mbar}$ & $1013-1263$ (absolute) \\
Flow rate (standard temperature and pressure (STP)) & $\mathrm{mL} / \mathrm{min}$ & $7.5-50$ \\
Residence time & $\mathrm{s}$ & $0.4-2.5$ \\
\hline
\end{tabular}

Modelling of $\mathrm{CHF}_{3}$ pyrolysis: Several researchers have already investigated the thermal decomposition of fluoroform $\left(\mathrm{CHF}_{3}\right)$ over a broad temperature and residence time range, as well as with shockwave techniques or turbulent reactors. The main products in the pyrolysis of $\mathrm{CHF}_{3}$ reported in literature are the valuable monomers TFE and HFP, but also undesired partly fluorinated alkanes and alkenes like $\mathrm{C}_{2} \mathrm{~F}_{6}, \mathrm{C}_{2} \mathrm{HF}_{3}, \mathrm{C}_{3} \mathrm{~F}_{8}$, and $\mathrm{C}_{2} \mathrm{~F}_{5} \mathrm{H}$, as well as toxic compounds like i- $\mathrm{C}_{4} \mathrm{~F}_{8}$ and $\mathrm{HF}$ [23]. It is generally agreed that the initial step in the synthesis of fluoromonomers is the highly endothermic decomposition of fluoroform yielding difluorocarbene $\left(: \mathrm{CF}_{2}\right)$ [24]. Hence, an efficient supply of heat is needed to keep the dehydrofluorination going. The decomposition of $\mathrm{CHF}_{3}$ starts up at $700{ }^{\circ} \mathrm{C}$ and is intensified by an increase of temperature and residence time. Reported activation energies for the decomposition of $\mathrm{CHF}_{3}$ are in the range of $244-295 \mathrm{~kJ} / \mathrm{mol}[24,25]$. By dimerization of the generated difluorocarbene, the main product TFE is formed, but dimerization of difluorocarbene is reversible under reaction conditions, which is experimentally evidenced by Couture et al. [26] in their studies to produce HFP out of TFE. The yield of TFE passes a maximum value at a certain reaction (residence) time in consequence of the consecutive reaction with difluorocarbene to HFP [27]. Thus, the formation of fluoromonomers by pyrolysis of fluoroform depends on the generation and consumption of difluorocarbene. The complete reaction network of $\mathrm{CHF}_{3}$ pyrolysis, which consists of seven reactions, is described in detail in Section 3.3.

In this study, the calculation of the $\mathrm{CHF}_{3}$ conversion was done based on the kinetic parameters (pre-exponential factor, activation energy) determined by respective own experiments. The rates of formation of the consecutive products tetrafluoroethylene (TFE), hexafluoropropylene (HFP), and perfluoroisobutene $(\mathrm{PFiB})$ were calculated based on the respective kinetic parameters reported in the literature. The differential equations describing both the $\mathrm{CHF}_{3}$ conversion and the product yields at different residence times and temperatures were solved by Matlab R2015b using ode 45 solver.

Life cycle analysis (LCA): The evaluation of the ecological and economical potential of the developed process (LCA) was carried out according to ISO 1404X standards with the software Simapro 
8.3.0 and the Database ecoinvent 3.3. The assessment criteria are the cumulative energy demand (CED) in version V1.09 and the 18 impact categories of the ReCiPe method midpoint $(\mathrm{H})$ v1.12/European $\operatorname{ReCiPe}(\mathrm{H})$.

\section{Results}

3.1. Calculation of Conversion and Yield in the Pyrolysis of $\mathrm{CHF}_{3}$

The pyrolysis of $\mathrm{CHF}_{3}$ can be regarded as a first order reaction:

$$
r_{\mathrm{CHF}_{3}}=-\frac{d c_{\mathrm{CHF}_{3}}}{d \tau}=k_{\mathrm{CHF}_{3}} c_{\mathrm{CHF}_{3}} .
$$

The reaction rate $\mathrm{r}\left(\mathrm{mol} \mathrm{m}^{-3} \mathrm{~s}^{-1}\right)$ is defined here based on the residence time $(\tau)$ in the tubular reactor and depends on the rate constant $k_{\mathrm{CHF} 3}(1 / \mathrm{s})$ and the concentration of $\mathrm{CHF}_{3}\left(\mathrm{~mol} \mathrm{~m}^{-3}\right)$. For an isothermal and ideal plug flow reactor, integration of Equation (11) yields the following conversion:

$$
\mathrm{X}_{\mathrm{CHF}_{3}}=1-e^{-k_{\mathrm{CHF}_{3}} \tau} .
$$

The assumption of a plug flow reactor is only valid in good approximation for a highly turbulent flow (Reynolds number Re $>2300$ ). For the microreactor used in this study, Re is defined as

$$
R e=\frac{u d_{h y d}}{v},
$$

where $u$ is the gas velocity (at reaction conditions), $d_{h y d}$ is the characteristic (hydraulic) diameter, and $v$ is the kinematic viscosity. For a quadratic channel with height and width s (both here $1 \mathrm{~mm}$ ), $d_{\text {hyd }}$ is given by the following ( $A$ : cross sectional area; $C$ : circumference):

$$
d_{\text {hyd }}=\frac{4 \cdot A}{C}=\frac{4 s^{2}}{4 s}=s .
$$

For the given microreactor, $R e$ is very small, for example, 23 for a typical residence time of $0.4 \mathrm{~s}$ and temperature of $875{ }^{\circ} \mathrm{C}$. Thus, the flow is strictly laminar under the applied conditions in this study.

For laminar flow, the conversion of $\mathrm{CHF}_{3}$ in a tubular reactor is usually calculated as follows [28]:

$$
\begin{gathered}
X_{\text {lam }}=1-\left(1-\frac{D a}{2}\right) \cdot e^{\frac{-D a}{2}}-\frac{D a^{2}}{4} \int_{\frac{D a}{2}}^{\infty} \frac{e^{-x}}{x} d x, \\
D a=k_{C H F 3}(T) \cdot \tau, \\
k_{\mathrm{CHF}_{3}}(T)=k_{\mathrm{CHF}_{3}, 0} e^{-\frac{E_{A}}{R T}}, \\
\tau=\frac{V_{\text {reactor }}}{\dot{V}_{\text {Feed }}(T)}=\frac{L_{\text {reaction zone }}}{u_{\text {Feed }}(T)} .
\end{gathered}
$$

$D a$ is the so-called Damköhler number. Solutions of the integral in Equation (15) are tabulated [29,30].

In the case of laminar flow, the assumption of plug flow behavior is not valid and usually a lower conversion (as determined by Equation (15)) is achieved compared with an ideal plug flow reactor (PFR) (Equation (12)). However, the advantage of the small dimensions (above all the small diameter) of the used microreactor is a relatively fast diffusion in the radial direction, that is, the characteristic 
time for radial diffusion, $\tau_{D}$, is much shorter than the average residence time $(\tau)$ [28]. In Equation (19), $r_{t}$ is the radius of reaction channel, and $D_{\text {mol }}$ is the diffusivity of gas $\left(\mathrm{N}_{2}\right)$.

$$
\tau_{D}=\frac{r_{t}^{2}}{D_{\text {mol }}} \ll \tau=\frac{L_{\text {reaction zone }}}{u_{\text {Feed }}(T)}
$$

In this study, the residence time $\tau(0.4-2.5 \mathrm{~s})$ is always higher than the characteristic time of diffusion $\tau_{D}(0.1 \mathrm{~s}$, determined by Equation (19)). In this case, we may use the axially dispersed plug flow model and the so-called axial dispersion coefficient $D_{a x}$, respectively, to inspect the deviation from an ideal PFR (see, for example, the work of [28]):

$$
\begin{gathered}
\frac{D_{a x}}{u L_{t}}=\frac{1}{B o}=\frac{D_{a x}}{u d_{t}} \frac{d_{t}}{L_{t}}, \\
D_{a x}=D_{m o l}+\frac{u^{2} d_{t}^{2}}{192 D_{m o l}} .
\end{gathered}
$$

In the Equations (20) and (21), $u$ is the gas velocity, and $d_{t}$ and $L_{t}$ are the diameter and length of the reactor, respectively. The Bodenstein number Bo represents the ratio of convective flux to diffusive flux [28]:

$$
B o=\frac{u L_{t}}{D_{a x}} .
$$

For Re higher than 10, the first term on the right-hand side of Equation $(21)\left(D_{m o l}\right)$ can be neglected and the $B o$ as a measure for the deviation from plug flow behavior reads as follows:

$$
\text { Bo }=192\left(\frac{L_{t}}{u}\right)\left(\frac{D_{m o l}}{4 r_{t}^{2}}\right)=192 \tau \frac{1}{4 \tau_{D}} \approx 50 \frac{\tau}{\tau_{D}} \quad(\text { for } R e>10) .
$$

In general, plug flow is almost reached if $B o>80$ [28]. In the used microreactor, $B o$ is always $>175$ $\left(875{ }^{\circ} \mathrm{C}, 0.4 \mathrm{~s}\right)$. Thus, Equation (12) is valid and was used to calculate the conversion of $\mathrm{CHF}_{3}$.

The yields and selectivities of TFE and HFP are calculated by the residual molar rates in $\mathrm{mol} / \mathrm{s}$ (reactor outlet) and the initial molar rate of $\mathrm{CHF}_{3}$ (Equations (24)-(27)). The factors 2 and 3 consider the stoichiometry of the respective reactions.

$$
\begin{gathered}
Y_{T F E}=2 \frac{\dot{n}_{T F E}}{\dot{n}_{\mathrm{CHF}_{3,0}}}, \\
Y_{H F P}=3 \frac{\dot{n}_{H F B}}{\dot{n}_{\mathrm{CHF} 3,0}}, \\
S_{T F E}=2 \frac{\dot{n}_{T F E}}{\dot{n}_{\mathrm{CHF}, 0}-\dot{n}_{\mathrm{CHF}}}=\frac{Y_{T F E}}{X_{\mathrm{CHF3}}}, \\
S_{H F P}=3 \frac{\dot{n}_{H F B}}{\dot{n}_{\mathrm{CFF}_{3,0}}-\dot{n}_{\mathrm{CHF}}}=\frac{Y_{H F P}}{X_{\mathrm{CHF3}}} .
\end{gathered}
$$

For the first order assumption, the rate constant is given (based on Equation (12)) by the following:

$$
k_{C H F 3}=-\ln \left(\frac{1-X_{C H F 3}}{\tau}\right) .
$$


The pre-exponential factor $k_{0}$ and the activation energy $E_{A}$ were determined by the Arrhenius equation (Equation (29) and the respective plot based on experiments at different temperatures (775 to $875^{\circ} \mathrm{C}$ ) and residence times ( 0.35 to $2.5 \mathrm{~s}$ ). All experiments were conducted at atmospheric pressure.

$$
\ln \left(k_{C H F 3}\right)=\ln \left(k_{C H F 3,0}\right)-\frac{E_{A}}{R} \frac{1}{T} .
$$

\subsection{Kinetic Parameters, Conversion, and Product Distribution in the Pyrolysis of $\mathrm{CHF}_{3}$}

Kinetic parameters: The experimental data are fitted with a least square fitting for the calculation of the kinetic parameters. The data are shown in Figure $4 \mathrm{a}$ and the straight lines are in good agreement with the first order approach. The values of $k_{C H F 3,0}$ and $E_{A}$ are listed in Figure $4 \mathrm{~b}$.

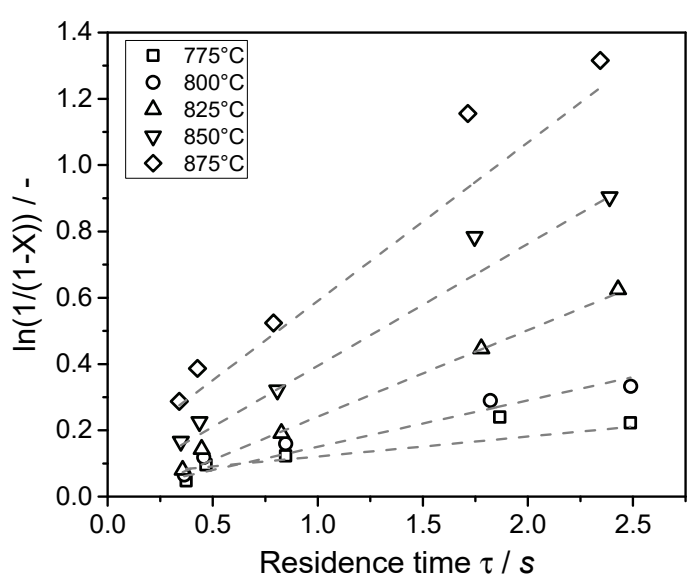

(a)

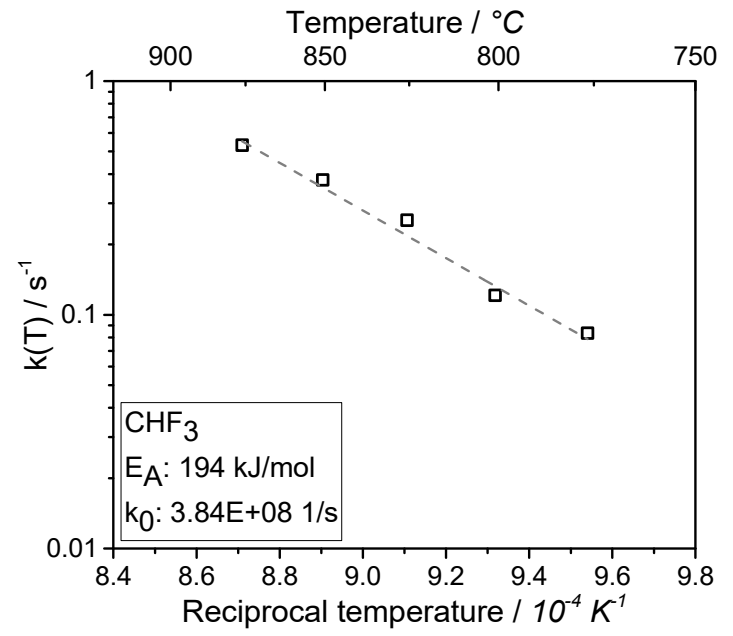

(b)

Figure 4. Measurement of kinetic parameters in the pyrolysis of $\mathrm{CHF}_{3}$ : (a) determination of $\mathrm{k}(\mathrm{T})$ at different temperatures, (b) Arrhenius plot for determination of $E_{A}$ and $k_{C H F 3,0}$.

First order assumption and conversion: The measured $\mathrm{CHF}_{3}$ conversion for different concentrations of fluoroform is shown in Figure 5a for three temperatures. The conversion is constant for each temperature, which is a clear indication of a first order reaction.

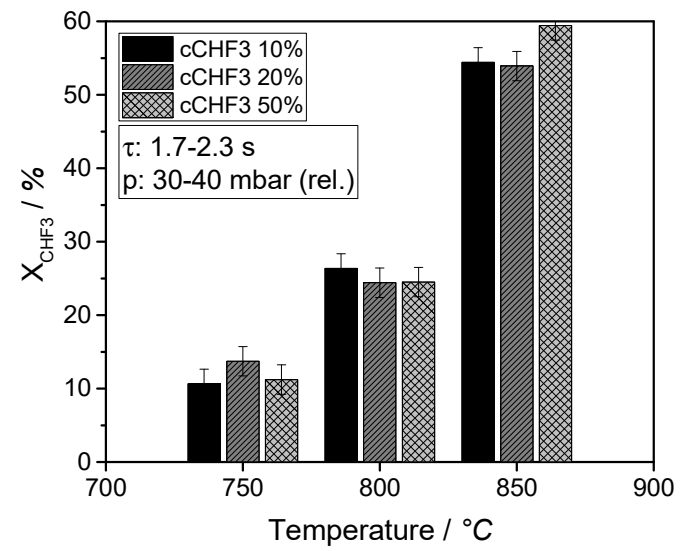

(a)

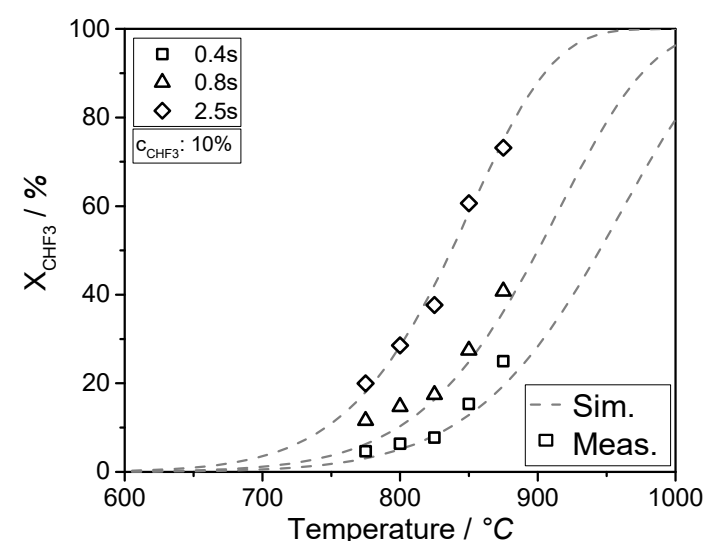

(b)

Figure 5. (a) Conversion of $\mathrm{CHF}_{3}$ for different temperatures and (b) comparison of simulated and measured conversion of $\mathrm{CHF}_{3}$ over temperature for different residence times.

In Figure $5 b$, the conversion of $\mathrm{CHF}_{3}$ is shown as a function of temperature for different residence times. The calculated $\mathrm{CHF}_{3}$ conversion (dashed lines) matches the experimental data (dots) quite well 
(for the assumption of a first order reaction). Measured conversion of about $25 \%$ at $875{ }^{\circ} \mathrm{C}$ and $0.4 \mathrm{~s}$ is in good agreement with $\mathrm{CHF}_{3}$ conversion of $27.3 \%$ in the experiments of Hauptschein et al. [12].

Product distribution: The products of $\mathrm{CHF}_{3}$ pyrolysis are practically only $\mathrm{C}_{2} \mathrm{~F}_{4}$ and $\mathrm{C}_{3} \mathrm{~F}_{6} \cdot \mathrm{C}_{2} \mathrm{~F}_{6}$ and $\mathrm{i}-\mathrm{C}_{4} \mathrm{~F}_{8}$ are only formed in traces at the highest measured temperatures. The yields and selectivities of TFE and HFP (as valuable products) at shortest and longest adjusted residence time are shown in Figures 6 and 7 in a temperature range of 775 to $875^{\circ} \mathrm{C}$. With increasing temperature and residence time, the yield and selectivity, respectively, of the consecutive product HFP $\left(\mathrm{C}_{3} \mathrm{~F}_{6}\right)$ increases. In this study, a maximum yield of $23 \%$ TFE $\left(0.4 \mathrm{~s}\right.$ at $\left.875{ }^{\circ} \mathrm{C}\right)$ and of $17 \%$ TFE and $35 \% \operatorname{HFP}\left(2.5 \mathrm{~s}\right.$ at $\left.875{ }^{\circ} \mathrm{C}\right)$ is achieved. Compared with yields of Hauptschein et al. [12], the generated yields of TFE and HFP are in the same range. Thus, with the same process parameters $\left(880^{\circ} \mathrm{C}\right.$ and $\left.0.4 \mathrm{~s}\right)$, the calculated yield by Equations (24) and (25) of Hauptschein et al. is $17.9 \%$ for TFE and $6.6 \%$ for HFP. The highest yield of $58.1 \%$ is reached at $960{ }^{\circ} \mathrm{C}$ and $0.3 \mathrm{~s}$. The maximum yield of fluoromonomers (52\%) is obtained in this study at lower temperatures (about $100{ }^{\circ} \mathrm{C}$ ) and longer residence times $(2.5 \mathrm{~s})$, which could be explained by the reversible dimerization of TFE to difluorocarbene and the consecutive reaction to HFP at the adjusted residence times [26].

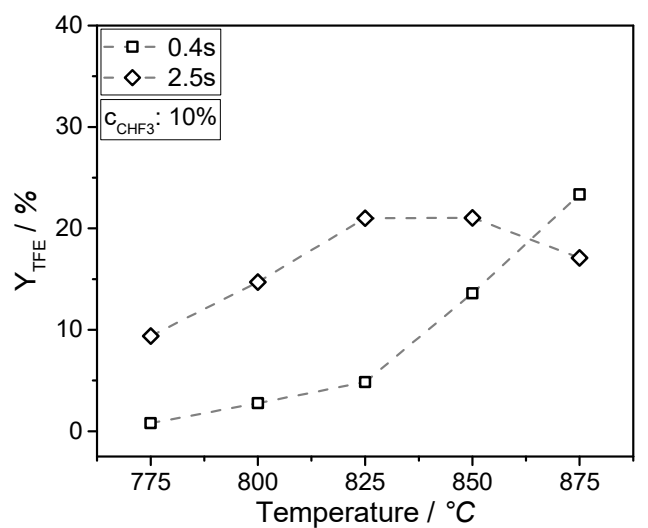

(a)

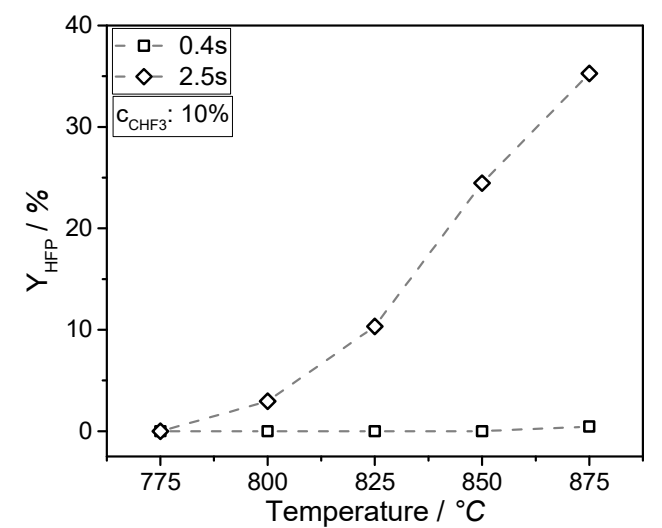

(b)

Figure 6. Measured product formation in the pyrolysis of $\mathrm{CHF}_{3}$ : (a) yield of $\mathrm{C}_{2} \mathrm{~F}_{4}$ and (b) yield of $\mathrm{C}_{3} \mathrm{~F}_{6}$ (line: guide for the eye, dot: experimental data).

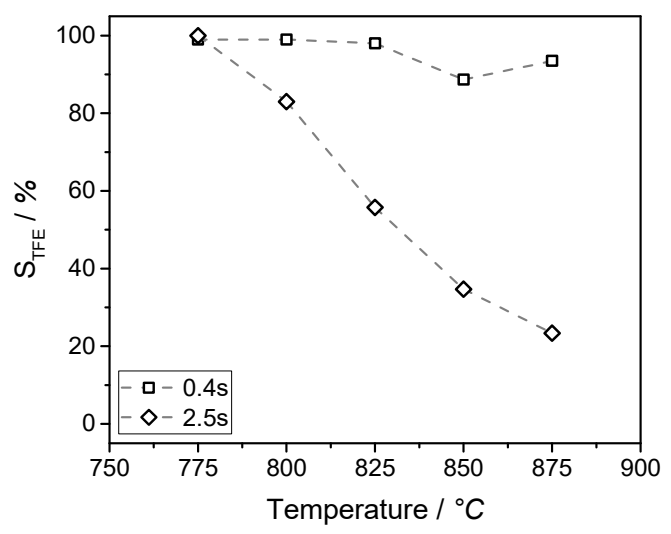

(a)

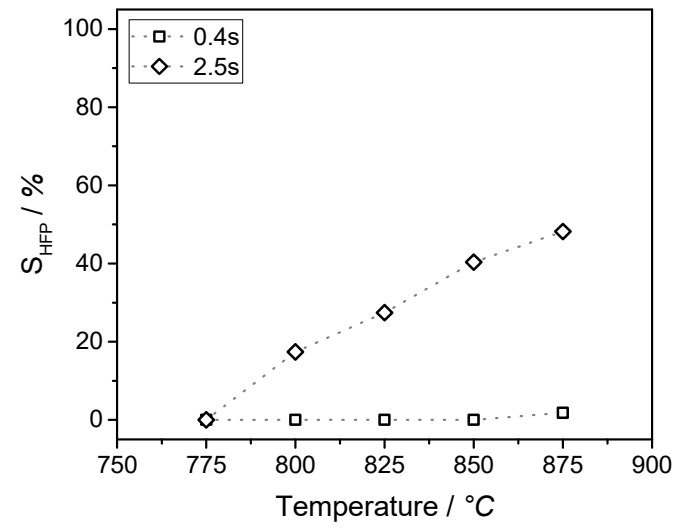

(b)

Figure 7. Selectivity of fluoromonomers TFE (a) and $\mathrm{HFP}(\mathbf{b})$ in the pyrolysis of $\mathrm{CHF}_{3}$ (line: guide for the eye, dot: experimental data).

Long-term process stability of $\mathrm{CHF}_{3}$-pyrolysis in the SiC-microreactor: After the evaluation of suitable process parameters, the $\mathrm{CHF}_{3}$ pyrolysis was carried out at residence times of 0.4 and $2.5 \mathrm{~s}$ for several hours to study the "long-term" microreactor stability and performance. Figure 8 shows that 
isothermal conditions and a stable reactor operation were reached in both cases after about $1 \mathrm{~h}$. The time of $1 \mathrm{~h}$ is necessary for heating the oven to target temperatures and purging all tubes and washing bottles with the same concentration of reaction products.

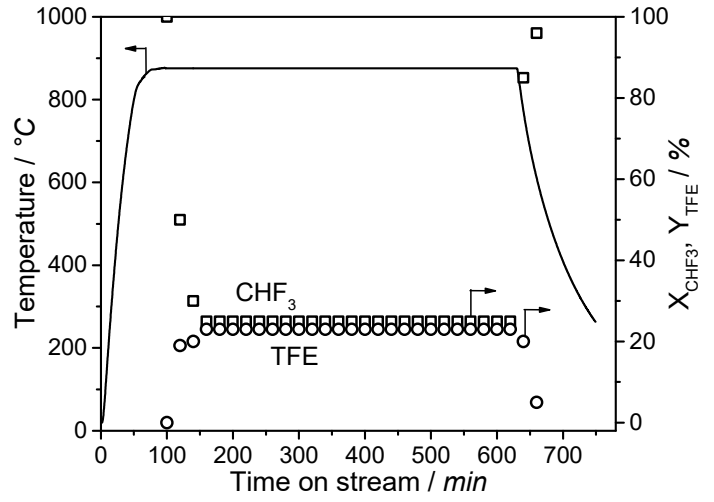

(a)

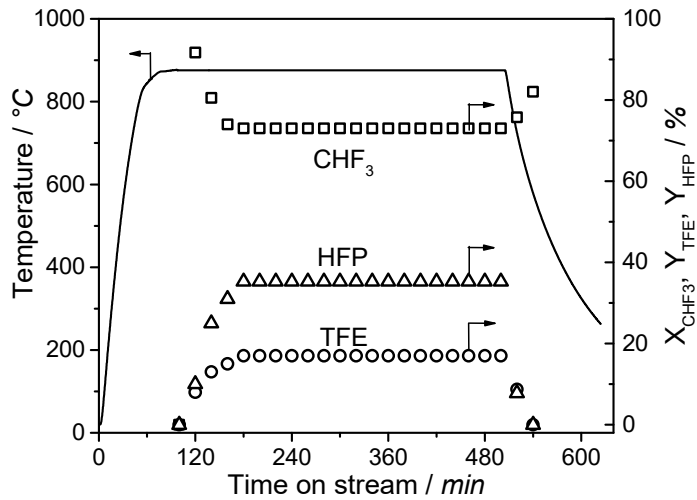

(b)

Figure 8. Time on stream: (a) production of $\mathrm{C}_{2} \mathrm{~F}_{4}(0.4 \mathrm{~s})$ and (b) production of $\mathrm{C}_{2} \mathrm{~F}_{4}$ and $\mathrm{C}_{3} \mathrm{~F}_{6}(2.5 \mathrm{~s})$ at $875^{\circ} \mathrm{C}$.

\subsection{Simulation of Product Distribution}

The gas phase pyrolysis of $\mathrm{CHF}_{3}$ at temperatures between 775 and $875{ }^{\circ} \mathrm{C}$ was examined in more detail using both experimental data and modeling techniques. The first step in the pyrolysis of $\mathrm{CHF}_{3}$ is dehydrofluorination to hydrogen fluoride $(\mathrm{HF})$ and difluorocarbene $\left(: \mathrm{CF}_{2}\right)$; see Equation (8) $[24,31,32]$. Similar to the reaction of R22, the generated difluorocarbene dimerizes immediately to TFE [33]. The formation of HFP—Equation (10)—takes place by consecutive reaction of TFE with another $\mathrm{CF}_{2}$ carbene. The overall reaction network can be described by a series of consecutive reactions listed in Table 6. The kinetic parameters for $\mathrm{CHF}_{3}$ decomposition were experimentally determined in this study. For the remaining consecutive reactions, literature references were used (Table 6).

The kinetic parameters of the reaction of $\mathrm{C}_{2} \mathrm{~F}_{4}$ (TFE) with a difluorocarbene radical $\left(\mathrm{CF}_{2}\right)$ to $\mathrm{C}_{3} \mathrm{~F}_{6}$ (HFP) were calculated by fitting $k_{4}(\mathrm{~T})$ for each temperature and by the Arrhenius plot. Compared with the study of Ainagos [34], $E_{A}$ is in the same range, but $k_{0}$ is lower (values in Table 6). The reaction network was then finally simulated with the kinetic parameters listed in Table 6. The comparison of experimental and simulated data is shown in Figure 9 for constant pyrolysis temperatures of $850{ }^{\circ} \mathrm{C}$ and $875^{\circ} \mathrm{C}$ and a residence time up to $3 \mathrm{~s}$. The measured and simulated (dimensionless) concentrations of the educt $\mathrm{CHF}_{3}$ and the products TFE, HFP, and PFiB are in good agreement.

Table 6. Kinetic parameters of the consecutive reaction network.

\begin{tabular}{ccccc}
\hline Reaction & $\mathbf{k}_{\mathbf{n}} \mathbf{( T )}$ & $\mathbf{k}_{\mathbf{0}}\left[\mathbf{s}^{\mathbf{- 1}} \mathbf{o r ~ s}^{\mathbf{- 1}} \mathbf{M}^{\mathbf{- 1}}\right]$ & $\mathbf{E}_{\mathbf{A}}[\mathbf{k J} / \mathbf{m o l}]$ & Literature \\
\hline$C H F_{3} \rightarrow H F+: C F_{2}$ & $\mathrm{k}_{1}$ & $4.16 \times 10^{8}$ & 195 & this study \\
\hline $2: C F_{2} \rightarrow C_{2} F_{4}(T F E)$ & $\mathrm{k}_{2}$ & $8.71 \times 10^{8}$ & 0 & Poltanskii [35] \\
\hline$C_{2} F_{4} \rightarrow 2: C F_{2}$ & $\mathrm{k}_{3}$ & $4.57 \times 10^{16}$ & 293 & Poltanskii [35] \\
\hline$C_{2} F_{4}+: C F_{2} \rightarrow C_{3} F_{6}(H F P)$ & $\mathrm{k}_{4}$ & $4.97 \times 10^{8}$ & 122 & $\begin{array}{c}\text { this study } \\
\text { (calc. from data) }\end{array}$ \\
\hline$C_{3} F_{6} \rightarrow C_{2} F_{4}+: C F_{2}$ & $\mathrm{k}_{5}$ & $1.91 \times 10^{13}$ & 333 & Poutsma. [36] \\
\hline$C_{3} F_{6}+: C F_{2} \rightarrow i-C_{4} F_{8}($ PFiB) & $\mathrm{k}_{6}$ & $1.20 \times 10^{16}$ & 385 & Bauer [37] \\
\hline
\end{tabular}




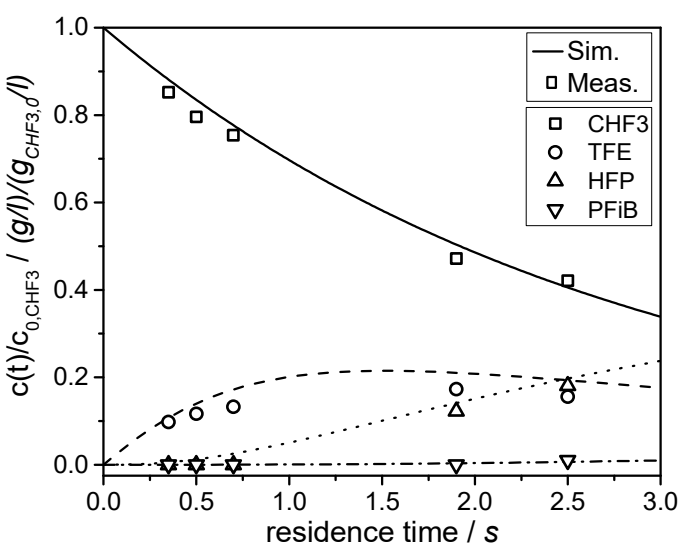

(a)

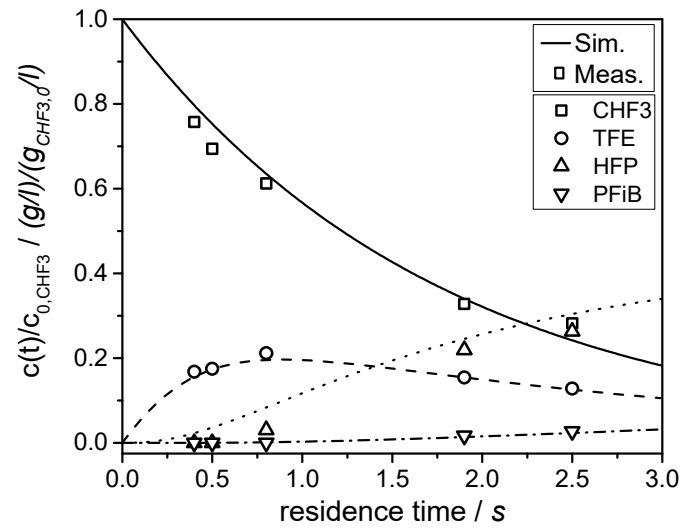

(b)

Figure 9. Simulation of $\mathrm{CHF}_{3}$ pyrolysis: (a) $850{ }^{\circ} \mathrm{C}$ and (b) $875^{\circ} \mathrm{C}$.

\subsection{Life Cycle Assessment (LCA)}

Environmental protection and resource efficiency gain increasing importance in politics and economics as a result of changing legislative frameworks or a shortage of raw materials. In addition, the transition to renewable energy resources has far reaching effects on the available energy mix for an industrial process. Under economic and environmental aspects like the Paris international climate agreement, new processes need to be more cost- and resource-efficient. Thus, the energetic evaluation of production processes has become an important part in process development in the last two decades. One possibility to evaluate a process regarding required energies, their ecological damage potential, and waste disposal is the life cycle assessment (LCA). Implementation of an LCA enables the direct comparison of different process routes and the identification of savings potential with regard to energy and raw materials [38].

In this work, a comparative LCA of the proposed new chlorine-free pyrolysis process and the incineration process of fluoroform, which is the actual state of the art for handling partly fluorinated compounds, was done. In addition, the current industrial R22 route to produce fluoromonomers was used for evaluating the savings potential of this new process route.

To compare these three processes, we started by analyzing the single process steps of the different process routes and set the system boundaries. Afterwards, the calculation of mass and material flows and the thermal and electric process energies took place on the basis of thermodynamic and reaction requirements. For a better comparability between the industrial R22 route and our lab scale process, a scale up for the handling of $300 \mathrm{tCHF}_{3} / \mathrm{a}$ was conducted. Evaluation criteria were the cumulative energy demand (CED) and the ReCiPe in different impact categories, like climate change, human toxicity, ozone depletion, and resource depletion.

\subsubsection{Functional Unit, System Boundaries, Material Flow, and Process Energy}

Our work compares the incineration of partly fluorinated alkanes (s. Table 1) with the newly developed process for recycling compounds originating from ECF (s. Table 2) and the R22 route (s. Table 2).

The first step contains the comparison of the incineration and pyrolysis of $1 \mathrm{~kg}$ of $\mathrm{CHF}_{3}$, which is defined as the functional unit (FU) in this work (Equation (30)).

$$
\mathrm{FU}=1 \mathrm{~kg} \mathrm{CHF} 3 .
$$

Afterwards, the amount of generated fluoromonomers (TFE and HFP), which is obtained by the pyrolysis of $1 \mathrm{~kg} \mathrm{CHF}_{3}\left(\mathrm{CHF}_{3}\right.$ route), is compared in a second step with the similar amount of fluoromonomer generated by the industrial $\mathrm{R} 22$ route. 
In all cases, only the production of the fluoromonomers (TFE, HFP) was considered, in order to simplify the researched process chains. All subsequent products, for example, fluoropolymers, that are generated by polymerization are neglected because the energy costs for their production and disposal are similar. The defined system boundaries of the LCA for incineration and pyrolysis of $1 \mathrm{~kg}$ of $\mathrm{CHF}_{3}$ are shown in Figure 10. The $\mathrm{CHF}_{3}$ route in Figure 10 consists of the supply of the $\mathrm{CHF}_{3}$ from the ECF by train, the pyrolysis step at the optimum process parameters $\left(875^{\circ} \mathrm{C}, 2.5 \mathrm{~s}, \mathrm{CHF}_{3}\right.$ conversion $73 \%$, and yield fluoromonomers $52 \%$ ). This is followed by the exhaust gas treatment by quenching the product gas, neutralization of gaseous $\mathrm{HF}$, and the following distillation of the generated monomers. The process of incineration of partly fluorinated compounds includes the $\mathrm{CHF}_{3}$ supply, the incineration step, and neutralization of the generated HF.
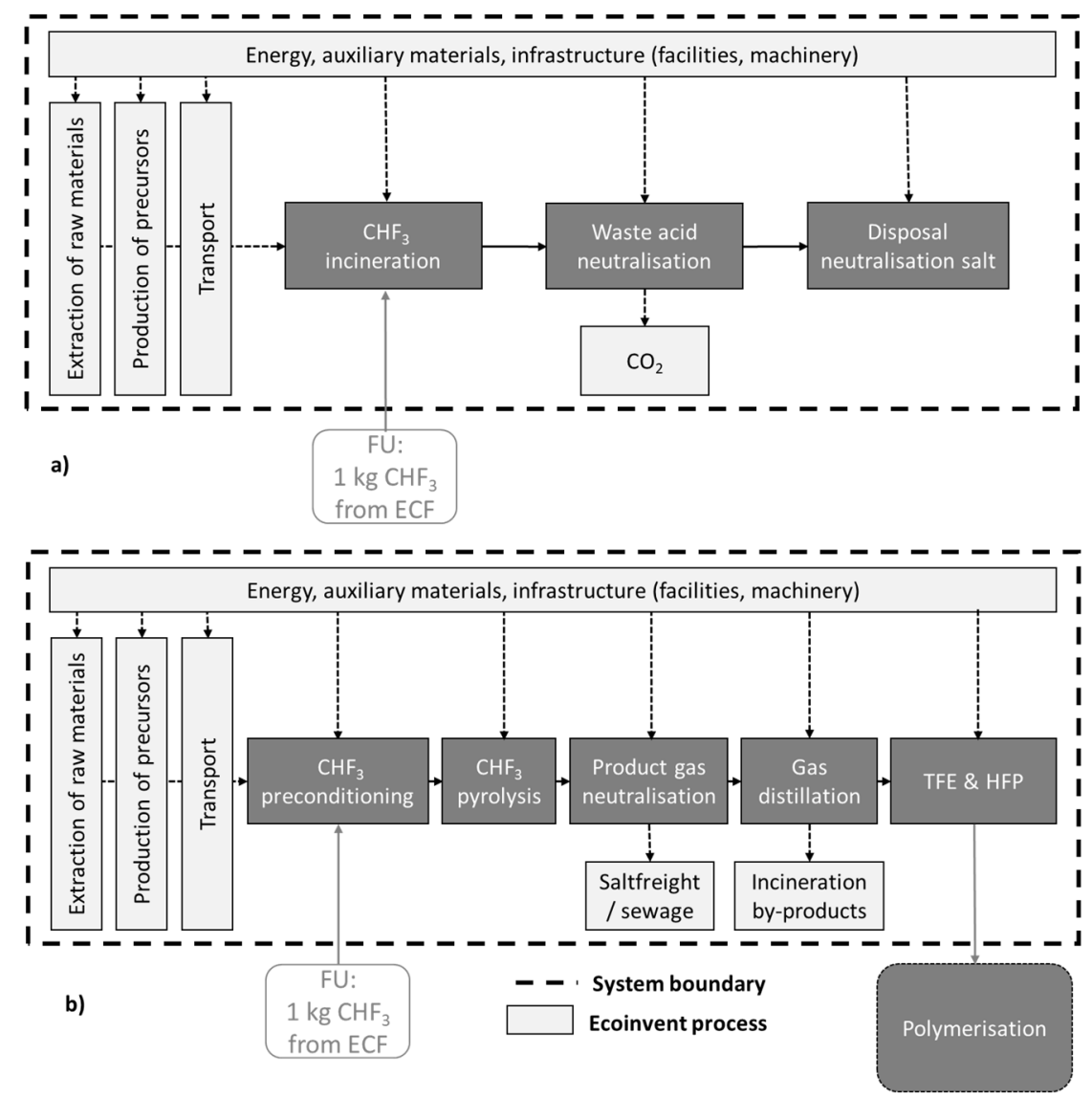

Figure 10. System boundaries for (a) incineration of $\mathrm{CHF}_{3}$ and (b) chlorine-free synthesis of TFE and HFP by pyrolysis of $\mathrm{CHF}_{3}$. ECF, electrochemical fluorination.

Additionally, the life cycle assessment is based on the following assumptions:

- No energetic or ecological allocations for $\mathrm{CHF}_{3}$ (by-product of ECF);

- No consideration of energetic and infrastructure processes for building the chemical plant, because of the theoretical scale up and its similarity to R22 pyrolysis;

- The supplied energy consists of the usual energy mix in Germany (2014);

- The energy demand for the $\mathrm{CHF}_{3}$ route is subjected to a conservative estimation, whereby a higher saving potential of the overall energy demand is possible. 
The generated data for energy and mass flows in the $\mathrm{CHF}_{3}$ route and $\mathrm{CHF}_{3}$ incineration are obtained in this study or estimated in a scale up of the $\mathrm{CHF}_{3}$ pyrolysis process. The data for the balancing of incineration of partly fluorinated compounds originate from an exhaust gas incineration plant. In contrast to the newly developed process to produce fluoromonomers, the standard process of TFE production, R22 pyrolysis, is already stored in the ecoInvent-database. Table 7 shows the heat and material flows for each of the compared processes.

Table 7. Mass balances and process energies for the incineration and pyrolysis of $1 \mathrm{~kg}$ of $\mathrm{CHF}_{3}$.

\begin{tabular}{|c|c|c|c|c|c|c|c|c|}
\hline & & \multicolumn{4}{|c|}{$\mathrm{CHF}_{3}$ Route } & \multirow{2}{*}{$\mathrm{CHF}_{3}$ Incineration } & \multicolumn{2}{|c|}{ ECF } \\
\hline & & Transport & Pyrolysis & Neutralization & Distillation & & HF & ECF \\
\hline Freight train & $\mathrm{tkm} / \mathrm{kg}$ & 0.9 & & & & & & \\
\hline natural gas & $\mathrm{kg} / \mathrm{kg}$ & & 0 & & & 2.60 & & \\
\hline Electricity & $\mathrm{kWh} / \mathrm{kg}$ & & 1.5 & 0.32 & 0.21 & & 0.69 & 1.22 \\
\hline $\mathrm{CHF}_{3}$ & $\mathrm{~kg} / \mathrm{kg}$ & 1 & & & 0.3 & 1 & & 1 \\
\hline $\mathrm{CH}_{4}$ & $\mathrm{~m}^{3} / \mathrm{kg}$ & & & & & & & 0.33 \\
\hline air & $\mathrm{kg} / \mathrm{kg}$ & & 0 & & & 50.65 & & \\
\hline $\mathrm{H}_{2} \mathrm{O}$ & $\mathrm{kg} / \mathrm{kg}$ & & 0 & & & 5.60 & & \\
\hline $\mathrm{CO}_{2}$ & $\mathrm{~kg} / \mathrm{kg}$ & & 0 & & & 7.79 & & \\
\hline $\mathrm{HF}$ & $\mathrm{kg} / \mathrm{kg}$ & & & 0.2 & & 0.86 & 1 & 0.85 \\
\hline $\mathrm{NaOH}(18 \%)$ & $\mathrm{kg} / \mathrm{kg}$ & & & 3.17 & & 9.49 & & \\
\hline $\begin{array}{l}\text { Salt sewage } \\
(\mathrm{NaF})\end{array}$ & $\mathrm{kg} / \mathrm{kg}$ & & & 0.6 & & 1.80 & & \\
\hline Waste water & $\mathrm{kg} / \mathrm{kg}$ & & & 3.4 & & 43.2 & & \\
\hline $\mathrm{N}_{2}$ & $\mathrm{~kg} / \mathrm{kg}$ & & 3.69 & & & 0 & & \\
\hline TFE/HFP & $\mathrm{kg} / \mathrm{kg}$ & & & & 0.54 & 0 & & \\
\hline $\mathrm{CaF}_{2}$ & $\mathrm{~kg} / \mathrm{kg}$ & & & & & & 2 & \\
\hline $\mathrm{H}_{2} \mathrm{SO}_{4}$ & $\mathrm{~kg} / \mathrm{kg}$ & & & & & & 2.5 & \\
\hline
\end{tabular}

\subsubsection{ReCiPe Impact Categories}

The environmental influences of the evaluated processes, incineration, and pyrolysis of $\mathrm{CHF}_{3}$, are shown in Figure 11 for the selected impact category. Under environmental aspects, the incineration of the $\mathrm{CHF}_{3}$ is the best process for handling partly fluorinated ECF waste streams in all investigated impact categories. However, the incineration of $\mathrm{CHF}_{3}$ generates no fluoromonomers; a closer look must be taken at the two remaining processes for producing TFE and HFP.

Comparison of the monomer production processes in Figure 12 clarifies that the standard R22 route causes the highest environmental effects in every impact category. The R22 route performs the worst in the impact categories of climate change, ozone, and fossil depletion, as well as human toxicity. In contrast to the actual industrial process, the $\mathrm{CHF}_{3}$ route gets significantly better environmental results in every single impact category. The saving potential in the categories of climate change and fossil depletion is about a factor of two, a factor of 10 for human toxicity, and a factor of 10,000 for ozone depletion. The advantages of the $\mathrm{CHF}_{3}$ pyrolysis in terms of ozone depletion and climate change result mainly from the high global warming potential (GWP) of $\mathrm{CHF}_{3}$ [17]. Additionally, the developed process avoids undesirable by-products, for example, $\mathrm{HF}$ contaminated $\mathrm{HCl}$, which improves the environmental performance even more. 

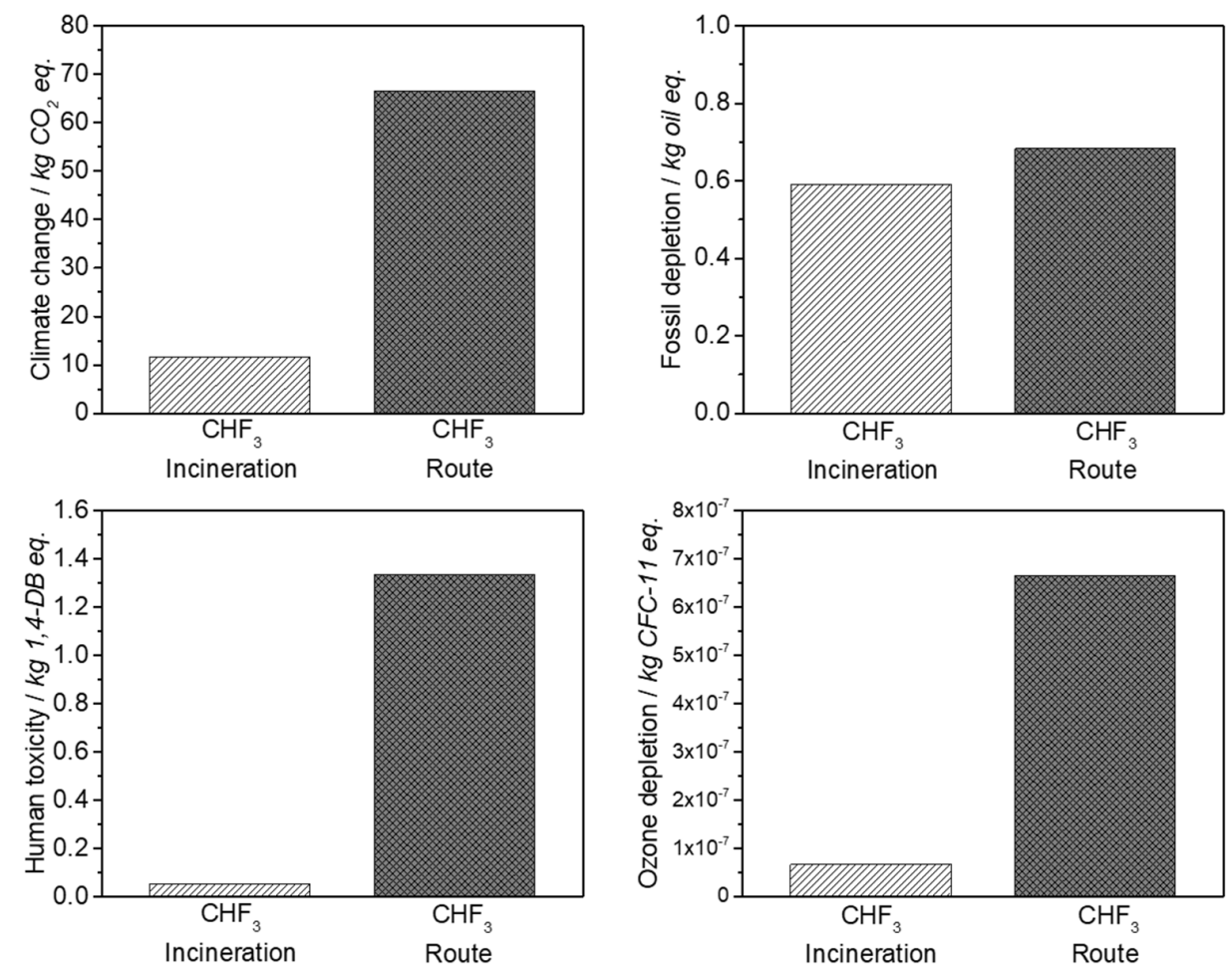

Figure 11. Selected categories with highest impact factors in the comparison of incineration and pyrolysis of $\mathrm{CHF}_{3}$.
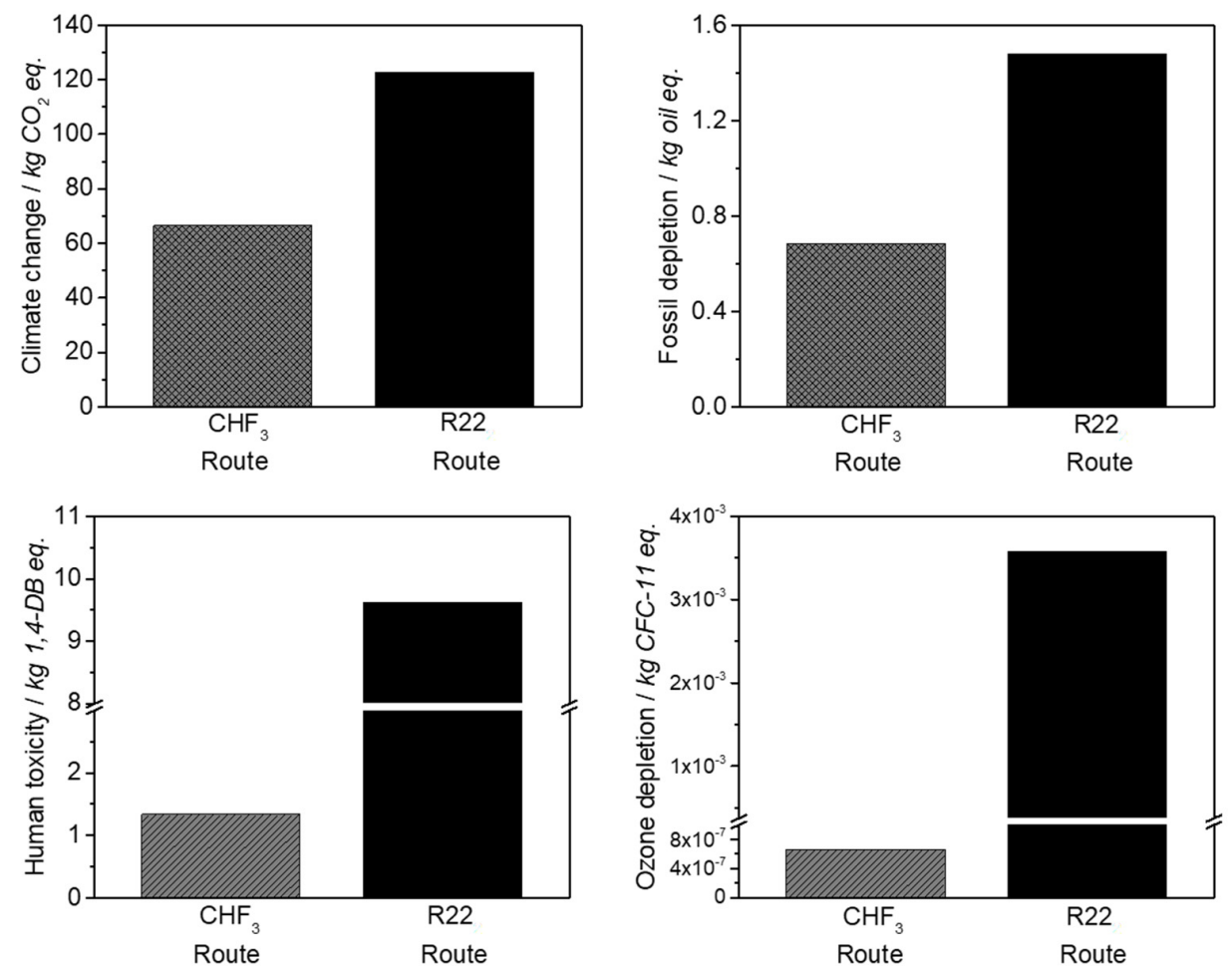

Figure 12. Selected categories with the highest impact factors in the comparison of monomer production processes $\mathrm{R} 22$ and $\mathrm{CHF}_{3}$ pyrolysis. 


\subsubsection{Cumulative Energy Demand (CED)}

The calculated CEDs of the compared processes are illustrated in Figure 13. Incineration of $\mathrm{CHF}_{3}$ has an energy demand of $28.3 \mathrm{MJ}$, while pyrolysis of $\mathrm{CHF}_{3}$ and the industrial $\mathrm{R} 22$ route consumes 45.1 MJ and 79.5 MJ, respectively. Under an energetic aspect, incineration of $\mathrm{CHF}_{3}$ is the best process to handle ECF waste stream, but at the end of the incineration, only $\mathrm{CO}_{2}$, high amounts of waste acids $(\mathrm{HF})$, and no valuable product are generated. Compared with incineration, the CED of the $\mathrm{CHF}_{3}$ route in Figure 13a show that by increasing the amount of energy by about $40 \%$, valuable monomers like TFE and HFP can be obtained out of a currently unused residue, which actually generates costs for its incineration and disposal.

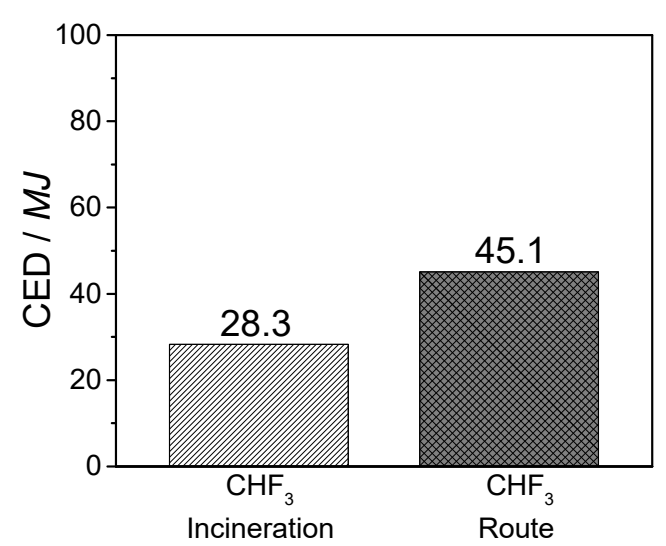

(a)

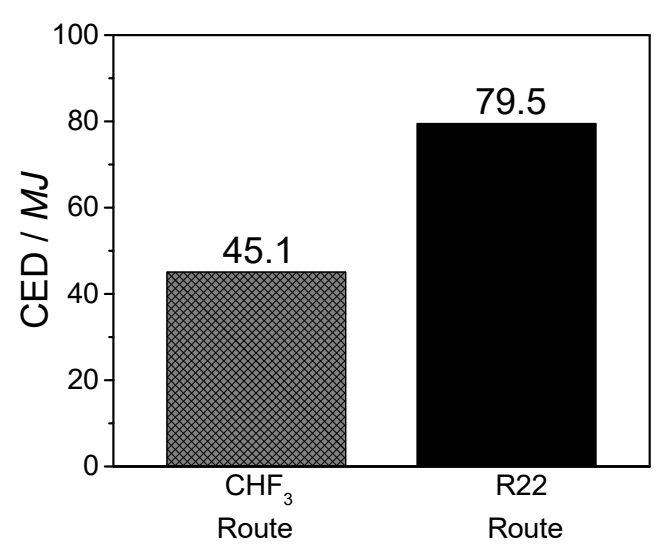

(b)

Figure 13. (a) Cumulative energy demand (CED) of the compared processes and (b) comparison of new developed chlorine-free against standard monomer production.

High savings potential of the developed pyrolysis process is evidenced by comparison with the industrial R22 route in Figure 13b. Originating from the residual $\mathrm{CHF}_{3}$ from ECF, $40 \%$ energy savings are obtained to produce the same amount of fluoromonomers. The energy demand for the single pyrolysis step of $\mathrm{CHF}_{3}$ is higher than that in $\mathrm{R} 22$ pyrolysis because of the higher reaction temperature, but the previous process steps of chlorination from methane to R22 and the required auxiliaries like $\mathrm{Cl}_{2}$, Sb-catalysts, and $\mathrm{HF}$ can be replaced completely.

Besides the material utilization of partly fluorinated residues, a chlorine-free synthesis of TFE and HFP requires the targeted production of $\mathrm{CHF}_{3}$ via the ECF and the following pyrolysis of the generated $\mathrm{CHF}_{3}$. The calculated energy demand of this combined process compared to the industrial R22 route is shown in Figure 14. The synthesis of $\mathrm{CHF}_{3}$ and the following pyrolysis of a mixture of $\mathrm{CHF}_{3}(10 \%)$ and nitrogen $(90 \%)$ has a nearly equal CED compared with the R22 route. Considering the assumption proved earlier of a first order reaction and the consequence of an independence of concentration in Figure 5a, the concentration of $\mathrm{CHF}_{3}$ in the educt stream is able to increase to $50 \%$ (Figure $5 \mathrm{a}$ ) and an energy saving of more than $10 \%$ is achieved.

Additionally, chlorine chemistry is fully substituted. Furthermore, the entire energy consumption of the process can be reduced by implementing gas burners instead of electrical heating of the reactors, with the disadvantage of a higher GWP, and additionally increasing the amount of fluorocarbon against nitrogen. Nevertheless, the advantage of the presented process, the reduction of four process steps in the $\mathrm{R} 22$ route to a one-step synthesis using partly fluorinated residues or a maximum two-step process with a target production of $\mathrm{CHF}_{3}$ and a following pyrolysis, is obvious. 


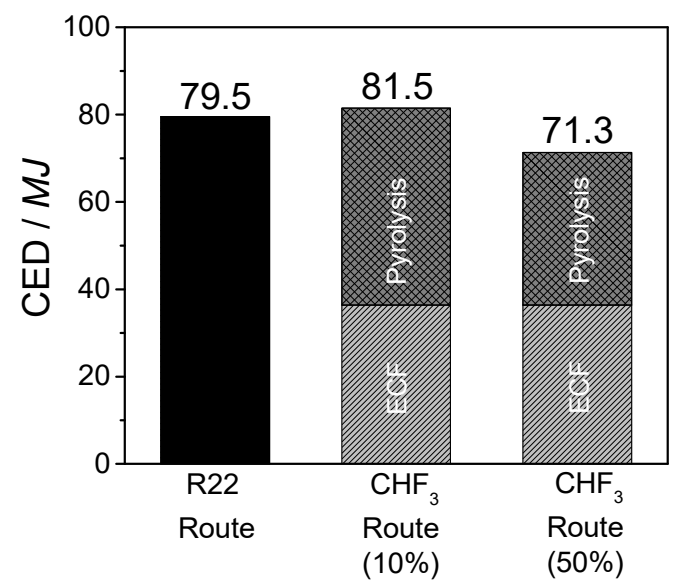

Figure 14. Comparison of the cumulative energy demand of new developed chlorine-free against standard monomer production.

\section{Discussion}

Partly fluorinated compounds (such as $\mathrm{CHF}_{3}$ ) originate from electrochemical fluorination. In this study, the chlorine-free synthesis of tetrafluoroethylene and hexafluoropropylene by pyrolysis of $\mathrm{CHF}_{3}$ was studied. The pyrolysis was conducted in a microreactor at atmospheric pressure in a temperature range of 775 to $875{ }^{\circ} \mathrm{C}$. Conversion of $\mathrm{CHF}_{3}$ turned out to be a first order reaction. The initial step of the gas phase pyrolysis of $\mathrm{CHF}_{3}$ is formation of $\mathrm{HF}$ and $\mathrm{CF}_{2}$ (difluorocarbene), which dimerizes immediately to $\mathrm{C}_{2} \mathrm{~F}_{4}$. With prolonged residence time, $\mathrm{C}_{3} \mathrm{~F}_{6}$ is obtained by the reaction of TFE and $\mathrm{CF}_{2}$. The activation energy $\left(E_{A}\right)$ and the pre-exponential factor $\left(k_{0}\right)$ of the decomposition of $\mathrm{CHF}_{3}$ to $\mathrm{HF}$ and $\mathrm{CF}_{2}$ were determined.

The formation of $\mathrm{C}_{2} \mathrm{~F}_{4}, \mathrm{C}_{3} \mathrm{~F}_{6}$, and $\mathrm{i}-\mathrm{C}_{4} \mathrm{~F}_{8}$ can be described by a reaction network consisting of six reactions. The simulation is in good agreement with the experimental data. The conversion of $\mathrm{CHF}_{3}$ reaches $73 \%$ at a temperature of $875{ }^{\circ} \mathrm{C}$, and a yield of about $52 \%$ fluoromonomers is obtained. Short residence times and/or high temperatures, isothermal conditions, and quenching of the product gas to avoid consecutive reactions maximizes the yield of fluoromonomers. These conditions could be realized in the ceramic microreactor used in this study.

The life cycle assessment for the developed $\mathrm{CHF}_{3}$ route demonstrates the ecological and economic benefit of this process. It is shown that the material utilization of $\mathrm{CHF}_{3}$ is preferable to incineration. In contrast to the generation of high amounts of waste acids at $\mathrm{CHF}_{3}$ incineration, the material utilization of $\mathrm{CHF}_{3}$ requires a higher energy expenditure $(40 \%)$, but generates high yields of the valuable products TFE and HFP. In comparison with the industrial $\mathrm{R} 22$ route, the developed $\mathrm{CHF}_{3}$ pyrolysis requires $40 \%$ less energy for the production of the same amount of fluoromonomers. Additionally, a reduction in terms of climate change and ozone depletion of $50 \%$ is obtained.

The developed process provides a sustainable synthesis of fluoromonomers with the material utilization of partly fluorinated compounds instead of their incineration. In this study, it is shown that the $\mathrm{CHF}_{3}$ pyrolysis process is stable with a time on stream of about $8 \mathrm{~h}$, shows no significant corrosion on the developed microreactor, and is thus ready for an industrial application. A scale up of the process is possible by employing multiple micro reactors in parallel or by a conventional scale up inspired by the R22 route with a tube bundle reactor, which is adjusted to the higher temperatures. Beneficial for the scale up is the proven first order reaction, which simplifies the reaction engineering. With regard to the tremendous saving potential in energy consumption, undesirable by-products, disposing waste materials, and the complete substitution of chlorine chemistry, the developed process is suitable to be transferred into the industrial scale. Especially, the developed reactor enables the pyrolysis of partly and perfluorinated gases and, therefore, becomes a big step in a complete closing of the fluorine cycle. 
Author Contributions: K.M. designed and performed the study and wrote the paper. A.S. helped in the design of the reactor sealing and in analyzing experimental as well as LCA data. T.G. was responsible for funding acquisition and A.J. supported the kinetic measurement and data evaluation. K.H. contributed the used gases and crosschecked the gas samples in the laboratories of $3 \mathrm{M}$.

Funding: Deutsche Bundesstiftung Umwelt (DBU) is gratefully acknowledged for financial support (reference number: 31819/01-31).

Acknowledgments: This publication was funded by the German Research Foundation (DFG) and the University of Bayreuth in the funding programme Open Access Publishing.

Conflicts of Interest: The authors declare no conflict of interest.

\section{References}

1. Ebnesajjad, S. Fluoroplastics, Volume 1, Non-Melt Processible Fluoropolymers, 2nd ed.; William Andrew: Waltham, MA, USA, 2015; ISBN 9781455731992.

2. Krämer, R. Social Megatrends Give Fluoropolymers a Boost. Kunstst. Int. 2016, 10, 82-86.

3. Costa, C.M.; Silva, M.M.; Lanceros-Méndez, S. Battery separators based on vinylidene fluoride (VDF) polymers and copolymers for lithium ion battery applications. RSC Adv. 2013, 3, 11404. [CrossRef]

4. Wang, H.; Sencadas, V.; Gao, G.; Gao, H.; Du, A.; Liu, H.; Guo, Z. Strong affinity of polysulfide intermediates to multi-functional binder for practical application in lithium-sulfur batteries. Nano Energy 2016, 26, 722-728. [CrossRef]

5. Edwards, J.W.; Small, P.A. Kinetics of Pyrolysis of Chlorodifluoromethane. Ind. Eng. Chem. Fund. 1965, 4, 396-400. [CrossRef]

6. Broyer, E.; Bekker, A.Y.; Ritter, A.B. Kinetics of the pyrolysis of chlorodifluoromethane. Ind. Eng. Chem. Res. 1988, 27, 208-211. [CrossRef]

7. Downing, F.B.; Benning, A.F. Pyrolyses of Chloro-Fluro Alkanes. U.S. Patent US2551573, 8 May 1951.

8. Chinoy, P.B.; Sunavala, P.D. Thermodynamics and kinetics for the manufacture of tetrafluoroethylene by the pyrolysis of chlorodifluoromethane. Ind. Eng. Chem. Res. 1987, 26, 1340-1344. [CrossRef]

9. Bjornson, G. Plasma Jet Conversion of Fluoroform. U.S. Patent US3471546, 7 October 1969.

10. Farlow, M.W. Process for Producing Tetrafluoroethylene from Perfluorocarbon Having At Least Three Carbon Atoms. U.S. Patent US2709182, 24 May 1955.

11. Gelblum, P.G. Disposal of Fluoroform (HFC-23). U.S. Patent US6806396 B2, 19 October 2004.

12. Hauptschein, M.; Fainberg, A.H. Production of Fluornated Compounds. U.S. Patent US3009966A, 21 November 1961.

13. Bauer, G.L. Process for Manufacturing Fluoroolefins. U.S. Patent US6919015 B2, 22 July 2005.

14. Aschauer, S.J.; Herdegen, J.; Schmidt, A.; Gerdes, T.; Hintzer, K.; Zipplies, T.; Willert-Porada, M. Kontinuierliches Verfahren zur chlorfreien Synthese von Tetrafluorethylen. Chem. Ing. Tech. 2014, 86, 529-537. [CrossRef]

15. Schmeisser, M.; Sartori, P. Die elektrochemische Fluorierung. Chem. Ing. Tech. 1964, 36, 9-14. [CrossRef]

16. Nagase, S.; Tanaka, K.; Baba, H. Direct Preparation of Partially Fluorinated Methane. BCSJ 1965, 38, 834-838. [CrossRef]

17. Houghton, E. Climate Change 1995: The Science of Climate Change (IPCC); Cambridge University Press: Cambridge, UK, 1998; ISBN 0521564360.

18. Nagase, S.; Tanaka, K.; Baba, H.; Abe, T. The Fluorination of Ethylene and Ethane. BCSJ 1966, 39, $219-222$. [CrossRef]

19. Sansotera, M.; Baggioli, A.; Ieffa, S.; Tedesco, M.; Sacchi, B.; Bianchi, C.L.; Navarrini, M.; Migliori, M.; Magagnin, L.; Navarrini, W. Catalytic microreactor with electrodeposited hierarchically nanostructured nickel coatings for gas-phase fluorination reactions. J. Fluor. Chem. 2018, 205, 22-29. [CrossRef]

20. Gutmann, B.; Köckinger, M.; Glotz, G.; Ciaglia, T.; Slama, E.; Zadravec, M.; Pfanner, S.; Maier, M.C.; Gruber-Wölfler, H.; Oliver Kappe, C. Design and 3D printing of a stainless steel reactor for continuous difluoromethylations using fluoroform. React. Chem. Eng. 2017, 2, 919-927. [CrossRef]

21. Kirschneck, D.; Marr, R. Anlagenkonzepte in der Mikroverfahrenstechnik. Chem. Ing. Tech. 2006, 78, $29-38$. [CrossRef] 
22. Jähnisch, K.; Hessel, V.; Löwe, H.; Baerns, M. Chemistry in microstructured reactors. Angezw. Chem. Int. Ed. Engl. 2004, 43, 406-446. [CrossRef] [PubMed]

23. Zhang, P.; Cao, L.; Pan, R.; Jiang, Z.; Qin, K.; Li, Q. A Study on the Pyrolysis of CHF3. Procedia Eng. 2013, 62, 337-341. [CrossRef]

24. Han, W.; Kennedy, E.M.; Kundu, S.K.; Mackie, J.C.; Adesina, A.A.; Dlugogorski, B.Z. Experimental and chemical kinetic study of the pyrolysis of trifluoroethane and the reaction of trifluoromethane with methane. J. Fluor. Chem. 2010, 131, 751-760. [CrossRef]

25. Hidaka, Y.; Nakamura, T.; Kawano, H. High temperature pyrolysis of CF3H in shock waves. Chem. Phys. Lett. 1991, 187, 40-44. [CrossRef]

26. Couture, M.J.; Gerner, H.M.B.; Gibbs, H.H. Process for Reducing the Formation of Process for Reducing the Formation of Polymer Attenedant the Pyrolyses of Tetrafluoroethylene. U.S. Patent US3578721A, 11 May 1968.

27. Yu, H.; Kennedy, E.M.; Mackie, J.C.; Dlugogorski, B.Z. An Experimental and Kinetic Modeling Study of the Reaction of CHF 3 with Methane. Environ. Sci. Technol. 2006, 40, 5778-5785. [CrossRef]

28. Jess, A.; Wasserscheid, P. Chemical Technology. An Integral Textbook; Wiley-VCH: Weinheim, Germany, 2013; ISBN 978-3-527-30446-2.

29. Forst, W.; Hoffmann, D. Die Г-Funktion. In Funktionentheorie erkunden mit Maple; Springer-Lehrbuch; Springer: Berlin/Heidelberg, Germany, 2012; pp. 281-298. [CrossRef]

30. Watson, G.A. Numerical Analysis, Proceedings of the Dundee Conference on Numerical Analysis; Springer: Berlin, Germany, 1976; Volume 506. [CrossRef]

31. Moon, D.J.; Chung, M.J.; Kim, H.; Kwon, Y.S.; Ahn, B.S. Pyrolysis of Trifluoromethane to Produce Hexafluoropropylene. Ind. Eng. Chem. Res. 2002, 41, 2895-2902. [CrossRef]

32. Wang, G.; Yin, H.; Yuan, S.; Chen, Z. Studies on oligomerization and kinetic of pyrolyzing trifluoromethane to tetrafluoroethylene and hexafluoropropylene. J. Anal. Appl. Pyrolysis 2015, 116, 27-33. [CrossRef]

33. Barnes, G.R.; Cox, R.A.; Simmons, R.F. The kinetics of the gas-phase thermal decomposition of chlorodifluoromethane. J. Chem. Soc. B 1971, 1176. [CrossRef]

34. Ainagos, A.F. Mechanism and Kinetics of Pyrolysis of Perfluorohexane. Kinet. Catal. 1991, 32, $720-725$.

35. Poltanskii, S.F.; Shevchuk, V.U. Thermal conversion of fluoromethane I. Kinet. Katal. 1968, 9, 496.

36. Poutsma, M.L. Chain elongation during thermolysis of tetrafluoroethylene and hexafluoropropylene: Modeling of mechanistic hypotheses and elucidation of data needs. J. Anal. Appl. Pyrolysis 2011, 92, $25-42$. [CrossRef]

37. Bauer, S.H.; Javanovic, S. The pyrolysis of octafluorocyclobutane-Revisited. Int. J. Chem. Kinet. 1998, 30, 171-177. [CrossRef]

38. Frischknecht, R.; Jungbluth, N.; Althaus, H.-J.; Bauer, C.; Doka, G.; Dones, R.; Hischier, R. Implementation of Life Cycle Impact Assessment Methods: Ecoinvent Report No. 3. v2.0. Available online: Esu-services.ch/ fileadmin/download/publicLCI/03_LCIA-Implementation.pdf (accessed on 20 June 2019).

(C) 2019 by the authors. Licensee MDPI, Basel, Switzerland. This article is an open access article distributed under the terms and conditions of the Creative Commons Attribution (CC BY) license (http://creativecommons.org/licenses/by/4.0/). 